\title{
СТЕЙКХОЛДЕРСКИЙ ПОДХОД К ИНИЦИАЦИИ ДЕЛОВЫХ ПРОЕКТОВ В РАМКАХ МНОГОСТОРОННИХ МЕЖГОСУДАРСТВЕННЫХ СОГЛАШЕНИЙ "
}

\author{
() 2020 Бариленко В.И. \\ доктор экономических наук, профессор \\ Департамент бизнес-аналитики Факультета налогов, аудита и бизнес-анализа \\ Финансовый университет при Правительстве Российской Федерации, Россия, Москва
}

Рассматриваются задачи и возможности использования стейкхолдерского подхода для аналитического обеспечения инициации и разработки деловых проектов в рамках многосторонних межгосударственных соглашений. Предлагается методика выявления проблем бизнеса и определения путей их решений при помощи сопоставления требований заинтересованных сторон, возможностей этого бизнеса и фактических показателей его деятельности. Рекомендуется создание постоянно действующей системы бизнес-анализа для обоснования и комплексной аналитической поддержки деловых проектов в условиях действующих интеграционных соглашений.

Ключевые слова: Стейкхолдерский подход, проблемы, бизнес-анализ, деловые проекты.

При рассмотрении вопросов развития межгосударственных интеграционных соглашений в сфере экономики их участники, в первую очередь, исходят из национальных интересов в глобальной конкурентной борьбе. Однако, как писал М.Портер «На международном рынке конкурируют фирмы, а не страны. Необходимо понять, как фирма создает и удерживает конкурентное преимущество, чтобы уяснить роль страны в этом процессе» [1].

Несмотря на последние геополитические события, устойчивые процессы глобализации приводят к тому, что география технологических процессов производства товаров и услуг, а также их послепродажного обслуживания все чаще выходит за пределы национальных границ различных государств, формируя международные цепочки создания добавленной стоимости. Причинами возникновения подобных глобальных цепочек могут быть и политические мотивы, но преобладают экономические соображения минимизации налогообложения, производственных и коммерческих издержек, получения доступа к новым технологиям и выхода на новые рынки.

При этом подобные мотивы лишь выражают интересы и потребности целого ряда ключевых игроков конкретного сектора рынка и взаимодействующих государств.

В качестве стейкхолдеров глобальных цепочек создания стоимости могут выступать ком- мерческие корпорации и некоммерческие организации

различных стран, центральные и муниципальные органы власти этих стран, международные организации и объединения, которые в ходе своего взаимодействия способны образовывать и различные коалиции, представляющие группы специальных интересов [2].

При этом проявляется взаимная зависимость этих заинтересованных сторон и системы международного сотрудничества, как объекта их интереса и влияния. Совокупность стейкхолдеров способна поддерживать экономику странучастниц многостороннего взаимодействия или, напротив, может затруднить и даже заблокировать возможности этого объединения действовать. При этом логично и само международное интеграционное объединение рассматривать как совокупность специфических взаимоотношений ее внутренних и внешних заинтересованных сторон [3].

Принципы стейкхолдерского подхода дают возможность создать постоянно действующий механизм инициации деловых проектов в рамках уже достигнутых якорных многосторонних межгосударственных соглашений. Создание такого механизма позволяет не ждать проявления стимулирующих бизнес и рост экономического сотрудничества функций таких соглашений, а сознательно управлять их развитием. Не пассивно ожидать благоприятного стечения

\footnotetext{
* Статья подготовлена по результатам исследований, выполненных за счет бюджетных средств по Государственному заданию Финуниверситета 2020 года
} 
обстоятельств для развития необходимых интеграционных процессов, а целенаправленно их формировать на основе изучения круга заинтересованных сторон каждого из подобных якорных соглашений, их экономических, геополитических, социально-культурных, оборонных и экологических потребностей, а также анализа возможностей их удовлетворения с учетом мировой стратегической ситуации и с использованием возможностей, уже заложенных в достигнутых ранее соглашениях. При этом учет потребностей ключевых заинтересованных сторон подобных соглашений позволит достигать синергетического эффекта, сбалансированно выполняя их требования и предупреждая возникновение потенциально конфликтных ситуаций [3].

Мотивами для инициации межгосударственных деловых проектов могут служить выявляемые проблемы бизнеса, признаками которых служат разрывы между требованиями его ключевых стейкхолдеров и фактическими показателями их удовлетворения в данной стране. Такой подход предопределяет необходимость учета и бизнес-возможностей возможных участников межгосударственных деловых проектов, которые могут трактоваться как условия или обстоятельства, позволяющее организации и ее стейкхолдерам удовлетворять свои потребности в тех или иных ценностях и получать определенную пользу.

Международный институт бизнес-анализа (IIBA) определяет бизнес-возможности как набор функций и конкретных действий, которые способно выполнять предприятие; компетенции, которыми оно располагает; продукты и услуги, которые оно может предоставлять; а также методы, которые оно использует для принятия и выполнения решений [4].

Основу формирования подобных возможностей составляет совокупность финансовых ресурсов, оборудования и других технических средств, технологий, патентов и секретов производства, баз данных и программных продуктов, систем управления, профессиональных навыков и знаний персонала, принципов и норм корпоративной культуры, формальных и неформальных взаимоотношений с ключевыми стейкхолдерами. Характеризуя потенциал фирмы, позволяющий воздействовать на все то, что способно обеспечить достижение ее целей и выполнение требований ее ключевых стейкхолдеров, бизнес-возможности отражают способности этой фирмы генерировать ценности для различных групп своих заинтересованных сторон.

Сопоставление конкретных потребностей заинтересованных сторон какой-либо корпорации с соответствующими имеющимися у нее возможностями позволяет обосновывать принципиально важные решения. Если потребности стейкхолдеров превышают возможности корпорации, это служит сигналом для инициации и разработки конкретных проектов (в том числе и международных) для восполнения дефицита бизнес-возможностей или для формирования их новых видов.

Если же в ранее выявленной проблемной области выяснится превышение возможностями конкретной корпорации фактических показателей выполнения требований к ней, то это будет свидетельствовать о том, что изучаемая проблема вызвана неполным использованием потенциала фирмы и разрешение этой проблемы может быть обеспечено ликвидацией допускаемых недостатков и корректировкой уже осуществляемых бизнес-процессов без необходимости инициации новых деловых проектов (тем более международных). Разумеется, при этом необходимо оценивать и способности данной корпорации реализовать свои возможности в рамках внутреннего рынка. Если это связано с большими трудностями, то и в такой ситуации решением проблем бизнеса может быть инициация проекта международного сотрудничества [5].

Очевидно, что использование подобного подхода потребует разработки и целенаправленного построения системы аналитического обеспечения управления развитием межгосударственных интеграционных отношений как на уровне крупных отечественных корпораций, так и на федеральном и региональном уровнях управления. Разумеется, ответственные государственные решения принимаются лидерами стран-участниц международных соглашений и реализуются соответствующими органами их исполнительной власти, но рекомендуемая система аналитического обеспечения способна на регулярной основе определять потребности этих стран в конкретных экономических проектах, обосновывать аргументы для ведения переговоров и принятия решений об их разработке, утверждении и непосредственной реализации.

При этом взаимодействующие страны и их экономические субъекты должны обладать до- 
ступом к необходимой информации и быть вооружены адекватным аналитическим инструментарием для самостоятельного обоснования и инициации конкретных проектов такого взаимодействия, иначе все межгосударственные соглашения и программы могут остаться лишь на бумаге [3].

Практическая реализация стейкхолдерского подхода для обоснования международных деловых проектов и комплексных интеграционных соглашений может основываться на систематическом проведении бизнес-анализа, ранее ориентированного на обеспечение управления изменениями бизнеса отдельных предприятий. Но методология этого нового направления аналитических исследований позволяет выявлять проблемы и обосновывать их решения при помощи осуществления изменений в самых разнообразных сферах человеческой деятельности (в том числе, и в сфере международных экономических отношений).

Концептуальной основой бизнес-анализа является использование стейкхолдерского подхода, предопределяющего, что долгосрочное устойчивое развитие любой социальноэкономической системы может быть обеспечено лишь при условии удовлетворения ею потребностей как самой этой системы, так и различных групп ее заинтересованных сторон, способных оказать существенное влияние на ее функционирование. К такого рода системам вполне могут быть отнесены и экономики отдельных стран, и разнообразные межгосударственные объединения, и транснациональные корпорации, и национальные экономические субъекты. Разумеется, в сфере международного экономического сотрудничества помимо факторов, присущих деятельности хозяйствующих субъектов, больше внимания необходимо уделять принципам международного экономического права [6] и специфическим геополитическим факторам. К последним можно отнести климатические из- менения, экологические проблемы, пандемию COVID-19, голод в Африке и масштабные миграционные потоки, спорадически возникающие вооруженные конфликты, противостояние процессов глобализации и тенденций ряда стран к региональной интеграции, рост влияния КНР и развитие многополярности мира, нарушающие принципы ВТО несправедливые экстерриториальные санкции западных стран и т.п.

Постоянное отслеживание и анализ изменений мировой экономической ситуации и всех перечисленных выше факторов, а также круга сторон, заинтересованных в международном сотрудничестве и препятствующих его развитию, их интересов и требований, имеющихся у них возможностей способны стать основой инициации подготовки и заключения межгосударственных экономических соглашений. В рамках подобных соглашений аналогичные задачи, связанные с выявлением круга стейкхолдеров и их требований, с сопоставлением этих требований с возможностями своего бизнеса и его фактическими параметрами, с обоснованием решений выявляемых при этом проблем, должны решать и экономические субъекты сотрудничающих стран. Именно решения их проблем, удовлетворяющие потребности их стейкхолдеров и государств в целом на основе расширения их бизнес-возможностей и должны служить мотивами инициации конкретных деловых проектов.

Следует отметить, что для реального формирования действенного и скоординированного на всех уровнях механизма аналитического обеспечения управления развитием международного экономического сотрудничества на базе стейкхолдерского подхода необходимы как масштабные меры научно-методического характера, так и комплекс правовых, административно-организационных, экономических стимулирующих и мотивационных, информационных, а также кадровых мероприятий.

\section{Библиографический список}

1. Портер М. Международная конкуренция. Конкурентные преимущества стран. М.: Международные отношения, 1993. С. 51.

2. Самсонов P.А., Бочаров С. Н. Ответственность стейкхолдеров при формировании глобальных цепочек создания добавленной стоимости // Управленец. 2018 Т. 9 № 4 С. 53-65.

3. Бариленко В.И. Использование принципов бизнес-анализа при подготовке многосторонних интеграционных соглашений в рамках ЕАЭС // РИСК: Ресурсы, Информация, Снабжение, Конкуренция. - 2020. - № 2.C. $153-159$. 
4. A Guide to the Business Analysis Body of Knowledge ${ }^{\circledR}$ (BABOK ${ }^{\circledR}$ Guide) Version 3.0 International Institute of Business Analysis, Toronto, Ontario, Canada, 2015. URL: http://www.theiiba.org / Дата обращения 12.12.2020.

5. Бариленко, В.И. Аналитическое обеспечение управления цифровыми возможностями бизнеса // РИСК: Ресурсы, Информация, Снабжение, Конкуренция.-2020._- № 4. - С. 153-159.

6. Принципы международного экономического права. http://mylawsuit.ru/publ/raboty/mezhdunarodnoe_pravo/ principy_mezhdunarodnogo_ehkonomicheskogo_prava/30-1-0-60 / Дата обращения 12.12. 2020. 